\title{
INOVAÇÃO ABERTA COMO UM INSTRUMENTO PARA A GERAÇÃO DE BENEFÍCIOS GLOBAIS: UM ESTUDO NA PLATAFORMA OpEIIDEO
}

OPEN INNOVATION AS A TOOL FOR GENERATING GLOBAL BENEFITS: A STUDY ON THE OpEnIDEO PLATFORM

\section{LA INNOVACIÓN ABIERTA COMO UN INSTRUMENTO PARA LA GENERACIÓN DE BENEFICIOS GLOBALES: UN ESTUDIO EN LA PLATAFORMA OpenIDEO}

MARÍNDIA BRACHAK DOS SANTOS

Doutoranda

Universidade Federal Santa Maria - Brasil

marindiabrachak@gmail.com

KALIEN ALVES KLIMECK

Mestre

Universidade Federal Santa Maria - Brasil kaklimeck@gmail.com

\author{
MARIA CAROLINA S. FAGUNDES DE OLIVEIRA \\ Mestre \\ Universidade Federal Santa Maria - Brasil \\ mc.sfagundes@gmail.com \\ FLAVIA LUCIANE SCHERER \\ Doutora \\ Universidade Federal Santa Maria - Brasil \\ flaviascherer@globo.com
}

Submetido em: 21/06/2016 Aprovador em: 10/10/2016

Doi: alcance.v23n4.p495-512

\section{RESUMO}

A inovação configura-se como um dos fatores fundamentais para a competitividade e para a sobrevivência das empresas no mercado global. Neste contexto, emerge a necessidade de implantar novas formas de inovação, nas quais as empresas têm o desafio de migrar da inovação fechada para novos conceitos, como inovação aberta, cocriação, design thinking e crowdsourcing. Nesta lacuna, insere-se o presente estudo que objetiva realizar um mapeamento dos desafios lançados na plataforma OpenIDEO no período de 2012 a 2013. Para tanto, realizou-se uma pesquisa descritiva, com abordagem qualitativa e análise de conteúdo do caso OpenIDEO, que consiste em uma plataforma de inovação aberta cujas pessoas do mundo todo participam por meio do envio de ideias para solucionar problemas globais. Verificou-se que no período analisado foram lançados 10 desafios a comunidade on-line. Estes desafios encontram-se alocados em 6 áreas temáticas, que são: inovação, sustentabilidade, jovens, violência contra civis, bem-estar ao envelhecer e acessibilidade. As atividades colaborativas lançadas contaram com 86 ideias vencedoras, sendo que 62 delas referem-se a 7 desafios que estão em fase de realização. Com base nos resultados, pode-se constatar que há um significativo envolvimento da comunidade on-line com os desafios lançados, visto que todos tiveram ideias, aplausos e seguidores.

Palavras-chave: Inovação aberta; Cocriação; Crowdsourcing. 


\begin{abstract}
Innovation is one of the important factors for the competitiveness and survival of businesses in the global market. In this context, there is a need to create new forms of innovation, in which companies face the challenge of migrating from closed innovation to new concepts such as open innovation, co-creation, designing thinking, and crowdsourcing. The present study is intended to fill this gap, by mapping the challenges launched in OpenIDEO platform in the period 2012 to 2013 . For this purpose, we performed a descriptive study with a qualitative approach and content analysis of the OpenIDEO case, consisting of an open innovation platform to which people around the world can submit ideas to solve global problems. It was found that in the period analyzed, ten challenges were launched in the online community. These challenges were assigned to six thematic areas: innovation, sustainability, young people, violence against civilians, wellbeing in old age, and accessibility. The collaborative activities launched included of 86 winning ideas, 62 of which related to seven challenges that are now in the implementation stage. Based on the results, it is seen that there is significant involvement of the online community in the challenges launched, as all the challenges received ideas, applause, and followers.
\end{abstract}

Keywords: Open innovation; Co-creation; Crowdsourcing.

\title{
RESUMEN
}

La innovación se plantea como uno de los factores fundamentales para la competitividad y para la supervivencia de las empresas en el mercado global. En este contexto emerge la necesidad de implantar nuevas formas de innovación, en las cuales las empresas enfrentan el desafío de migrar de la innovación cerrada hacia nuevos conceptos tales como innovación abierta, cocreación, design thinking y crowdsourcing. El presente estudio se inserta en este espacio con el objetivo de realizar un mapeamiento de los retos lanzados en la plataforma OpenIDEO en el período de 2012 a 2013. Para ello se realizó una investigación descriptiva, con un enfoque cualitativo y análisis de contenido del caso OpenIDEO, que consiste en una plataforma de innovación abierta en la cual participan personas de todo el mundo por medio del envío de ideas para solucionar problemas globales. Se observó que en el período analizado se lanzaron 10 desafíos para la comunidad on-line. Estos desafíos se encuentran ubicados en 6 áreas temáticas, a saber: innovación, sostenibilidad, jóvenes, violencia contra civiles, bienestar al envejecer y accesibilidad. Las actividades colaborativas lanzadas contaron con 86 ideas vencedoras, 62 de las cuales se refieren a 7 desafíos que están en fase de realización. Con base en los resultados se puede constatar que hay un significativo envolvimiento de la comunidad on-line con los desafíos lanzados, visto que todos tuvieron ideas, aplausos y seguidores.

Palabras clave: Innovación abierta; Cocreación; Crowdsourcing.

\section{INTRODUÇÃO}

As transformações ocorridas no cenário global fizeram com que a inovação adquirisse uma maior amplitude e importância no contexto empresarial, não se relacionando apenas às atividades inerentes ao ambiente interno da organização, mas também aos múltiplos atores e cenários com os quais se relaciona. Durante anos, a lógica de que a empresa deveria deter o controle absoluto sobre o processo de inovação foi considerada como a melhor maneira para o desenvolvimento de ideias bem-sucedidas no mercado (CHESBROUGH, 2012). No entanto, no transcorrer das últimas décadas, observou-se uma mudança de perspectiva no entendimento acerca do grau de abertura do processo de inovação, com a consequente introdução do termo "inovação aberta", em alternativa ao modelo dominante de "inovação fechada". Juntas, essas duas concepções representam dois extremos de um contínuo que classifica 0 ato de transformar e inovar.

Essa perspectiva, denominada de forma inicial por Chesbrough (2003), como inovação aberta, sustenta a noção de que o processo de inovação deve ser mais colaborativo, ao buscar desenvolver conhecimento a partir de diversos atores externos. Por meio de tal inovação, as empresas não precisam ser necessariamente as criadoras das ideias, tendo em vista que, mais importante que o pioneirismo, é a gestão das ideias internas e externas, a manutenção do capital intelectual e o compartilhamento com outras organizações de ideias que sejam válidas para alavancar o modelo empresarial. 
A partir deste modelo de inovação e com o advento da internet e a conectividade à disposição de milhões de pessoas, iniciam-se novas interações sociais e desencadeia-se uma força democrática e descentralizada de participação na sociedade, que vai além das fronteiras institucionais. Essas forças, para Ramaswamy e Gouillart (2010, p. 245), "possuem o intuito de gerar novas formas de engajamento coletivo, de colaboração e cocriação de valor" e devem-se ao fato de as pessoas do mundo todo terem começado a apresentar um comportamento social inovador, ou seja, começarem a se reunir para executar tarefas nas quais não se possuía uma remuneração específica (HOWE, 2009), pois os propósitos para realizar tais atividades partiam de uma motivação comum, na qual a resolução de um problema consiste na recompensa pelo trabalho.

E ao se deparar com a importância desse novo parâmetro de se perceber a inovação, justifica-se o presente trabalho, que busca elucidar as plataformas de colaboração em massa na qual pessoas, de diferentes localidades no mundo, podem contribuir com ideias criativas para a resolução de problemas que afetam o planeta. Principalmente ao atentar que a implementação de plataformas de inovação na internet pode contribuir para aumentar a transparência do processo de inovação, em particular, da proteção dos direitos de propriedade intelectual (CHU, 2013).

Neste sentido, ao conhecer-se que existem muitas plataformas on-line, disponíveis em todo o mundo, que possibilitam transformar pessoas em editores de ideias e soluções, independente de sua formação e experiência (SCHEMMANN et al., 2016), o presente estudo tem como objeto de averiguação a IDEO, empresa de reconhecimento mundial que instituiu uma plataforma de inovação aberta denominada OpenIDEO.

Por meio de tal plataforma, membros da comunidade on-line podem resolver desafios dos mais variados âmbitos de forma coletiva (IDEO, 2013). Esta ferramenta de colaboração social está disponível sem restrições para que as pessoas possam participar e colaborar com suas ideias. Assim, com base no objeto de estudo, emerge a seguinte questão de pesquisa: Quais são as temáticas norteadoras dos desafios lançados no site OpenIDEO no período de 2012 a 2013 ?

O estudo alinha-se ainda com o panorama que retrata o momento de produção acerca da temática de open innovation. Em uma busca junto à Web of Science, conheceu-se que o tema tem ganhado atenção ao longo do tempo e vem gradativamente aumentando, destacando os anos de 2015, 2013, 2014, 2012 e 2011, como os que mais recepcionaram trabalhos em torno do assunto. Tais informações contemplam para a atualidade da temática, que ganhou maior atenção no decorrer dos últimos cinco anos.

No entanto, ainda se percebe uma falta de estudos que abarquem as ideias desenvolvidas e trabalhadas nessas plataformas. Por isso, o estudo objetiva realizar um mapeamento dos desafios lançados no site OpenIDEO no período de janeiro de 2012 a dezembro de 2013. Para tanto, utilizou-se de uma pesquisa descritiva, com abordagem qualitativa e da análise de conteúdo para a construção deste trabalho.

Para uma melhor organização deste estudo, além desta introdução, apresenta-se a revisão de literatura, contendo os aspectos relacionados à inovação aberta e alguns novos conceitos, como a cocriação, o design thinking e o crowdsourcing, além de uma apresentação acerca da plataforma analisada. Após, discorre-se sobre o método de coleta e análise dos dados e, em seguida, são descritos e discutidos os resultados obtidos.

\section{A INOVAÇÃO ABERTA COMO MEIO PARA GERAR BENEFÍCIOS GLOBAIS}

A inovação configura-se como um dos fatores fundamentais para a competitividade e para a sobrevivência das empresas no mercado. A partir do conhecimento de que a inovação depende de elementos que nem sempre podem ser encontrados em suas fontes internas, as organizações buscam alternativas para além de suas fronteiras, como meio de identificar ideias e tecnologias que sejam úteis em seu processo inovador (CHESBROUGH, 2003).

Neste entender, o conhecimento externo surge como um potencial motor de inovação, dada as diferentes perspectivas que emergem diante de conhecimentos combinados e acessados dentro e fora dos limites organizacionais das empresas, atribuindo-lhes competências antes difíceis de alcançar de forma isolada (SILVA; SILVA, 2015; CHESBROUGH, 2012). Abrangendo, com isso, questões como trabalho em equipe e alocação dos colaboradores de maneira produtiva e criativa dentro de uma organização.

É por meio do compartilhamento da criatividade para a resolução conjunta de problemas que se torna possível explorar diferentes habilidades e experiências que diferentes pessoas possuem e que podem contribuir com o grupo (BESSANT; TIDD, 2009). Levar uma ideia inovadora adiante depende de todo tipo de insumo vindo 
de diferentes pessoas e perspectivas. Desta forma, pondera-se que a inovação não é um ato solitário, mas um jogo de múltiplos participantes.

Para Chesbrough (2012), o conhecimento está cada vez mais disponível e as empresas não podem mais depender exclusivamente de seu conhecimento interno, necessitando adquirir inovações e propriedade intelectual de outras organizações parceiras. Com isso, percebe-se que uma mudança fundamental na forma como as empresas geram novas ideias e as colocam no mercado resulta em um novo modelo de inovação, denominado open innovation ou inovação aberta, um paradigma, no qual o conhecimento externo e interno passou a se interrelacionar dentro das organizações, por meio de trocas entre diversos agentes (SILVA; SILVA, 2015).

Este novo modelo de inovação, cunhado por Chesbrough em 2003, tem por objetivo descrever de forma estruturada um modelo de gestão que admite que as empresas podem e devem usar ideias e tecnologias externas para acelerar o processo de inovação, além de buscar caminhos alternativos, como a inserção em redes. De forma complementar, Bessant e Tidd (2009) sugerem que as organizações precisam abrir os seus processos de inovação, ampliar suas buscas para além de seus limites, gerenciando um conjunto de conexões e relacionamentos em rede.

Por isso, construir e gerenciar redes e conexões tornou-se a exigência vital para a inovação (BESSANT; TIDD, 2009). O que é complementado por Chesbrough (2012) ao abordar que o pensamento da inovação aberta muda o papel da função da pesquisa; ele expande o papel dos pesquisadores internos a fim de incluir não apenas a geração de conhecimento, mas também a intermediação do conhecimento. Observa-se, assim, que o foco principal não está na criação de conhecimento, e sim no seu fluxo.

Ademais, no entendimento de Chu (2013), os sistemas e as instituições econômicas têm grandes efeitos sobre o comportamento das empresas com relação a sua participação em práticas de inovação aberta. A percepção de que apenas uma empresa não pode suprir todo o campo de conhecimento faz com que grandes empresas se organizem em redes de relacionamentos ao redor do mundo e busquem o auxílio na internet como forma para diminuir as distâncias e permitir possibilidades de colaboração cada vez mais promissoras.

Felin e Zenger (2013) argumentam que a incerteza ambiental e a complexidade da inovação e do conhecimento levaram a um aumento da permeabilidade das fronteiras organizacionais e a necessidade de que as organizações passem a interagir com o seu ambiente e com as partes interessadas de forma mais aberta. Por isso, a noção de inovação aberta abrange uma ampla gama de atores externos, incluindo utilizadores, clientes, fornecedores, universidades e concorrentes.

Neste ponto, Ramaswamy e Gouillart (2010) defendem que as mudanças nos negócios e na sociedade trazem o conceito de cocriação que consiste na prática do desenvolvimento de sistemas, produtos e serviços por meio da colaboração com os clientes, gestores, colaboradores e outros atores que possuam interesse na empresa. Para dar início a tal processo, faz-se necessário a criação de uma plataforma de engajamento (como um site na internet), por meio da qual pessoas do mundo inteiro poderão contribuir com suas ideias.

Com isso, Ramaswamy e Gouillart (2010) destacam que as empresas e a sociedade estão se movendo rumo a uma visão de engajamento cocriativo baseado nos indivíduos e em suas experiências. Um engajamento que envolve indivíduos e instituições e que ocorre dentro e fora das organizações.

É neste sentido que Chesbrough (2012) destaca a necessidade de se inovar a própria inovação. Ou seja, enquanto os modelos tradicionais relacionam a criatividade ao ambiente da empresa, o novo modelo de inovação está pautado em duas realidades: a primeira, que ressalta a existência de meios eficazes para ultrapassar as fronteiras convencionais da empresa e aproveitar as ideias vindas de toda parte do mundo; e a segunda, que se relaciona ao fato de que parte das pessoas portadoras de conhecimento no mundo não faz parte de um determinado grupo isolado, mas estão distribuída em múltiplas instituições.

E a partir do momento que as empresas abrem seu processo de inovação para que possam se beneficiar de talentos distribuídos por todo o mundo, Ramaswamy e Gouillart (2010) evidenciam que esse processo pode ser melhorado e tornado mais eficaz por meio da aplicação do design thinking. De acordo com Macedo, Miguel e Filho (2015), o design thinking envolve o processo de geração de ideias em um grupo multidisciplinar como foco na resolução de problemas, assim, a utilização do design vai além da aparência dos produtos, sendo aplicado na concepção de soluções, que englobam os aspectos estratégicos do negócio (BONINI; SBRAGIA, 2011).

A ideia é pensar o processo de inovação como um instrumento cocriativo de interações, que passa a abranger uma gama de participantes e utiliza-se do poder da visualização de experiências para gerar novas 
percepções. Por meio do design thinking cocriador, os projetistas de plataformas dentro das empresas desenvolvem um modelo mental voltado para as experiências, isto é, utilizam-se dos conhecimentos dos participantes para realizar mudanças significativas em seus processos.

Neste sistema de criação colaborativa, Howe (2009) atenta para um comportamento que permeia grupos de pessoas no mundo todo, que é a reunião de indivíduos em prol de um único objetivo: criar soluções viáveis, úteis e criativas que irão beneficiar comunidades para além das fronteiras nacionais. Emerge assim, um novo conceito de criação colaborativa, o crowdsourcing, que consiste em um novo meio para aquisição de trabalho barato, no qual as pessoas usam seus momentos ociosos do cotidiano para criar conteúdo, resolver problemas e até mesmo para trabalhar em projetos de pesquisa e desenvolvimento.

O crowdsourcing consiste em um novo processo de criação e desenvolvimento de produtos e experiências por meio da colaboração entre empresas, consumidores e parceiros (LIMA et al., 2015). Para que este processo aconteça, Howe (2009) destaca que o crowdsourcing usa-se da tecnologia para incentivar níveis inéditos de colaboração e trocas, significativas entre pessoas, com as formações mais diversas, das mais distantes localizações geográficas.

Para Howe (2009), as comunidades on-line estão na essência do crowdsourcing, em que as pessoas costumam contribuir com projetos, por pouco ou nenhum dinheiro, visto que no contexto do crowdsourcing, a colaboração é a própria recompensa. Nesta direção, entre as empresas que utilizam o crowdsourcing, pode-se citar a Innocentive, que conta com 140 (cento e quarenta) mil cientistas espalhados pelo mundo, abordando problemas difíceis de Pesquisa e Desenvolvimento (P\&D) para as empresas que fazem parte da lista da Fortune 500 .

Outro exemplo promissor, segundo Ramaswamy e Gouillart (2010), é a plataforma de engajamento da Ashoka na internet, a Changemakers.com. Esta plataforma consiste em uma comunidade on-line de pessoas interessadas em inovação social. Por meio do portal, as pessoas discutem problemas, compartilham histórias e participam de grupos. A Ashoka desenvolve várias competições colaborativas, sendo cada uma delas concentrada numa questão social diferente, aceitando contribuições a cada três meses. Todas as ideias são postadas on-line para a comunidade observar cada uma e selecionar. No final da competição, um júri escolhe três finalistas. Então, a comunidade on-line vota nos escolhidos e o vencedor é premiado.

Nesta linha de pensamento, Howe (2009) complementa que o crowdsourcing requer a colaboração entre pessoas desconhecidas, distantes no mundo todo e unidas apenas por interesses comuns. É uma das vertentes pelas quais as estratégias de inovação aberta podem ser implementadas (GASSMANN; ENKEL; CHESBROUGH, 2010). E, para tanto, torna-se necessário buscar a integração entre os usuários e os potenciais consumidores às etapas iniciais do processo de inovação, como forma de compreender suas necessidades latentes e captar seus conhecimentos (LIMA et al., 2015).

Apesar de ser um tema em desenvolvimento, ressalta-se que este é um recurso que mal se começou a usar (HOWE, 2009). Tapscott e Williams (2011) acrescentam que a composição de uma equipe de voluntários de todo o mundo por meio de uma plataforma da internet, que permite propor soluções e gerenciar informações, revela-se como um novo paradigma que "vira de cabeça para baixo" de boa parte da sabedoria convencional.

Para tanto, a criação de plataformas colaborativas, em nível global, indica uma nova era de inovações e de mudanças, nas quais os colaboradores e inúmeros talentos do mundo todo estarão a não mais do que alguns cliques de distância. Para Tapscott e Williams (2011), partes destas mudanças emergem em virtude da lacuna que indica a falta de organização e coordenação das entidades responsáveis por resolver as grandes catástrofes mundiais e que não têm respondido aos anseios de uma massa global ansiosa por resoluções rápidas e eficazes.

Esta nova plataforma aberta, de compartilhamento global, permite que uma rede de voluntários forneça dados e informações úteis, de forma mais rápida que os tradicionais canais burocráticos poderiam fornecer. Neste enfoque, Tapscott e Williams (2011) salientam que o novo limiar da inovação econômica e social almeja por pessoas criativas e que possuam interesse em explorar novas ferramentas on-line para participarem de iniciativas coletivas que almejem tornar o mundo mais próspero, mais justo e mais sustentável.

A partir de plataformas de inovação aberta, como a Openldeo, que será descrita na seção de resultados, dispõe-se de um novo motor de inovação que permite que as comunidades cooperem em áreas de interesse, esforços e desafios comuns. 


\section{MÉTODO DE ESTUDO}

Com o propósito de atender ao objetivo proposto, este estudo caracteriza-se, quanto à abordagem, como uma pesquisa qualitativa, seguindo aos preceitos de Richardson (2008) ao explanar que os estudos que empregam uma abordagem qualitativa podem descrever a complexidade de determinado problema, analisar a interação de certas variáveis e compreender e classificar processos dinâmicos vividos por grupos sociais. Configura-se, também, como uma pesquisa descritiva, que tem por propósito a descrição das características de determinada população (GIL, 2010).

Já no que se refere aos procedimentos técnicos, o estudo caracterizou-se como um estudo de caso da empresa OpenIDEO (www.openideo.com), o qual consiste em uma plataforma de inovação aberta cujas pessoas do mundo todo participam enviando ideias que buscam soluções para a solução de problemas globais. Entre as motivações para analisar este site, pode-se citar as mudanças nos sistemas tradicionais de inovação para a colaboração em massa em plataformas globais que têm despertado a atenção de toda a sociedade.

A coleta de dados para a concretização do estudo contou com a realização de duas etapas: pesquisa bibliográfica e documental. Na primeira etapa, realizou-se uma revisão bibliográfica para investigar e entender os novos conceitos relacionados à inovação e às plataformas de inovação aberta. $E$ a segunda etapa vem ao encontro do exposto por Beuren (2004), ao apontar que a pesquisa documental se baseia em materiais que ainda não receberam um tratamento analítico ou que podem ser reelaborados de acordo com os objetivos da pesquisa. Desta forma, foi realizado um mapeamento dos projetos no período de janeiro de 2012 a dezembro de 2013. A partir dos projetos encontrados verificaram-se as etapas e os estágios de cada desafio lançados no site. Após esse processo, descreveram-se as ideias vencedoras e procurou-se verificar se as ideias vencedoras, em fase de realização, estão sendo aplicadas na sociedade.

Para a análise e tratamento dos dados, optou-se pela utilização da análise de conteúdo, por entender-se que é um método apropriado quando o fenômeno a ser observado é a comunicação (MALHOTRA, 2001). Tratase de um tipo de análise que ocorre por meio de descrições objetivas e sistemáticas do conteúdo das comunicações, tendo como finalidade a interpretação dessas mesmas comunicações.

\section{APRESENTAÇÃO E ANÁLISE DOS RESULTADOS}

Este capítulo atende ao objetivo principal da pesquisa, que se propõe a realizar um mapeamento dos desafios lançados na plataforma OpenIDEO no período de janeiro de 2012 a dezembro de 2013. Em um primeiro momento é discorrido sobre o caso Openldeo e, a seguir, são apresentados os resultados coletados.

\section{$O$ caso: OpenIDEO}

A IDEO, empresa de design conhecida mundialmente, iniciou em 2010 uma plataforma de inovação aberta chamada OpenIDEO. Como a principal premissa de uma ferramenta de colaboração social, o OpenIDEO é aberto para que qualquer pessoa possa participar e colaborar com ideias, visando ao bem social e/ou ambiental. Por meio do acesso on-line à plataforma, membros da comunidade de todas as partes do mundo podem enviar ideias e se envolver nos desafios para resolvê-los de forma coletiva.

Semelhante a um processo formal de inovação, as ideias são apresentadas como "desafios". Estes desafios são lançados por parceiros do site, os chamados sponsors, e recebem ideias de resolução. Essas ideias passam por três fases de refinamento até a premiação e algumas delas são desenvolvidas e implementadas.

Com isso, o processo é disposto seguindo um fluxo de etapas. A primeira fase é a inspiração, que procura compartilhar histórias e experiências. A segunda é a conceituação, que utiliza as ideias da fase anterior para criar uma ideia única. Em seguida, tem-se a fase de avaliação, em que ocorrem "aplausos" e refinamentos cujos conceitos se unem para gerar grande impacto. E ao receberem interesse e incentivo (aplausos) da comunidade do site, os desafios progridem para a fase seguinte, em que a própria comunidade escolhe quais são as melhores ideias para serem selecionadas.

O site não disponibiliza incentivos financeiros aos vencedores. Esses são reconhecidos pela contribuição em parte da solução de grandes problemas globais. Todos os conceitos são gerados com base na creative 
commons. Desta forma, estes conceitos podem ser reproduzidos, alterados e reutilizados por qualquer pessoa no mundo.

De acordo com Aiga (2011), a plataforma OpenIDEO permite que, por meio de um processo colaborativo, a geração de ideias torne-se mais eficaz, por ser inclusiva e aberta a colaboradores que não são necessariamente especialistas, e muitas vezes, podem estar inseridos em um contexto similar ao desafio proposto.

A OpenIDEO destaca-se por estimular milhares de usuários a engajarem-se na criação de soluções para problemas sociais de extrema relevância para o mundo. Dada a importância desta plataforma, tem-se 0 fato de que vários desses desafios têm gerado ideias que estão sendo desenvolvidas em diversos países.

Diante do conhecimento da plataforma OpenIDEO e com base nos resultados encontrados, verificou-se que os desafios lançados para a comunidade on-line no período da pesquisa totalizaram 10 desafios. Estes foram ordenados pela data de início e estão dispostos no Quadro 1:

Quadro 1: Desafios lançados na plataforma OpenIDEO entre janeiro de 2012 e dezembro de 2013

\begin{tabular}{|c|c|c|c|}
\hline $\mathbf{N}^{0}$ & Título do desafio & Objetivo principal & Principais dados \\
\hline 1 & $\begin{array}{l}\text { Como criar uma experiência de } \\
\text { eleição acessível para todos? }\end{array}$ & $\begin{array}{l}\text { Melhoria na acessibilidade da } \\
\text { eleição para pessoas com } \\
\text { deficiência e outras limitações }\end{array}$ & $\begin{array}{l}\text { 832 Seguidores; } 435 \text { Inspirações } \\
\text { para ideias; } 154 \text { Ideias com } \\
\text { Aplausos; } 20 \quad 20 \quad \text { Ideias } \\
\text { refinadas/avaliadas; } 11 \text { Ideias } \\
\text { vencedoras; em realização }\end{array}$ \\
\hline 2 & $\begin{array}{l}\text { Como podemos apoiar os } \\
\text { empreendedores da internet } \\
\text { na criação e crescimento de } \\
\text { empresas globais } \\
\text { sustentáveis? }\end{array}$ & $\begin{array}{l}\text { Identificar formas de melhorar o } \\
\text { ambiente on-line para Startups }\end{array}$ & $\begin{array}{l}1154 \text { Seguidores; } \\
\text { Inspirações para ideias; } 159 \\
\text { Ideias com Aplausos; } 20 \text { Ideias } \\
\text { refinadas/avaliadas; } 10 \text { Ideias } \\
\text { vencedoras; em realização }\end{array}$ \\
\hline 3 & $\begin{array}{l}\text { Como podemos desenvolver } \\
\text { jovens com competências, } \\
\text { informações e oportunidades } \\
\text { para obter sucesso no mundo } \\
\text { do trabalho? }\end{array}$ & $\begin{array}{l}\text { Identificar soluções para ajudar } \\
\text { os jovens a buscar emprego }\end{array}$ & $\begin{array}{l}990 \text { Seguidores; } 353 \text { Inspirações } \\
\text { para ideias; } 149 \text { Ideias com } \\
\text { Aplausos; } \quad 20 \quad \text { Ideias } \\
\text { refinadas/avaliadas; } 6 \text { Ideias } \\
\text { vencedoras; em realização }\end{array}$ \\
\hline 4 & $\begin{array}{l}\text { Como podemos gerenciar o } \\
\text { lixo e o descarte de eletrônicos } \\
\text { para proteger a saúde humana } \\
\text { e o meio ambiente? }\end{array}$ & $\begin{array}{l}\text { Encontrar maneiras de gerenciar } \\
\text { o lixo eletrônico para melhor } \\
\text { proteger a saúde humana e } 0 \\
\text { meio ambiente }\end{array}$ & $\begin{array}{l}536 \text { Seguidores; } 199 \text { Inspirações } \\
\text { para ideias; } 106 \text { Ideias com } \\
\text { Aplausos; } 20 \quad 2 \text { Ideias } \\
\text { refinadas/avaliadas; } 9 \text { Ideias } \\
\text { vencedoras; em realização }\end{array}$ \\
\hline 5 & $\begin{array}{l}\text { Como podemos identificar e } \\
\text { celebrar as empresas que } \\
\text { inovam para o benefício global } \\
\text { e inspirar outras empresas a } \\
\text { fazerem o mesmo? }\end{array}$ & $\begin{array}{l}\text { Examinar o papel da empresa } \\
\text { como indutor de inovação e } \\
\text { prosperidade beneficiando o } \\
\text { mundo e moldando a sociedade } \\
\text { de forma positiva e sustentável }\end{array}$ & 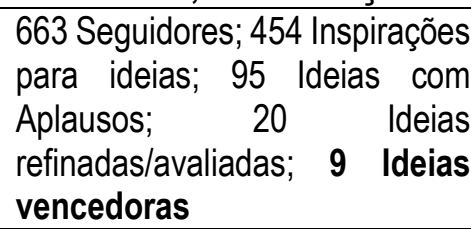 \\
\hline 6 & $\begin{array}{l}\text { Como podemos inspirar e } \\
\text { capacitar as comunidades a ter } \\
\text { mais iniciativas para tornar } \\
\text { seus ambientes locais } \\
\text { melhores? }\end{array}$ & $\begin{array}{l}\text { Como rejuvenescer nossos } \\
\text { ambientes locais para inspirar e } \\
\text { capacitar as comunidades para } \\
\text { torná-los melhores }\end{array}$ & $\begin{array}{l}560 \text { Seguidores; } 269 \text { Inspirações } \\
\text { para ideias; } 102 \text { Ideias com } \\
\text { Aplausos; } \quad 20 \quad \text { Ideias } \\
\text { refinadas/avaliadas; } 10 \text { Ideias } \\
\text { vencedoras; em realização }\end{array}$ \\
\hline 7 & $\begin{array}{l}\text { Como podemos criar } \\
\text { comunidades saudáveis dentro } \\
\text { e fora do local de trabalho? }\end{array}$ & $\begin{array}{l}\text { Explorar como as pessoas } \\
\text { podem ser melhor apoiadas em } \\
\text { seu local de trabalho para fazer } \\
\text { mudanças positivas para a sua } \\
\text { saúde e bem-estar }\end{array}$ & $\begin{array}{l}1159 \quad \text { Seguidores; } \\
\text { Inspirações para ideias; } 240 \\
\text { Ideias com Aplausos; } 20 \text { Ideias } \\
\text { refinadas/avaliadas; } 10 \text { Ideias } \\
\text { vencedoras; em realização }\end{array}$ \\
\hline
\end{tabular}




\begin{tabular}{|c|c|c|c|}
\hline 8 & $\begin{array}{l}\text { Como podemos coletar } \\
\text { informações em áreas de difícil } \\
\text { acesso para prevenir a } \\
\text { violência em massa contra } \\
\text { civis? }\end{array}$ & $\begin{array}{l}\text { Buscar forma de prevenir } \\
\text { violência deliberada em massa } \\
\text { contra civis em áreas de difícil } \\
\text { acesso }\end{array}$ & 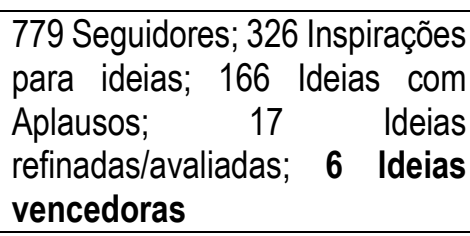 \\
\hline 9 & $\begin{array}{l}\text { Como podemos manter o bem- } \\
\text { estar e prosperar à medida que } \\
\text { envelhecemos? }\end{array}$ & $\begin{array}{l}\text { Entender como ajudar as } \\
\text { pessoas a tomar decisões e a } \\
\text { buscar um estado de bem-estar } \\
\text { à medida que envelhecem }\end{array}$ & $\begin{array}{l}744 \text { Seguidores; } 317 \text { Inspirações } \\
\text { para ideias; } 133 \text { Ideias com } \\
\text { Aplausos; } \quad 20 \quad r \quad \text { Ideias } \\
\text { refinadas/avaliadas; } 6 \text { Ideias } \\
\text { vencedoras; em realização }\end{array}$ \\
\hline 10 & $\begin{array}{l}\text { Como podemos inspirar os } \\
\text { jovens a cultivar a sua } \\
\text { confiança na criatividade? }\end{array}$ & $\begin{array}{l}\text { Projetar divertidas, inspiradoras } \\
\text { e novas maneiras de ajudar } \\
\text { adolescentes e jovens em todo } \\
\text { mundo a preservar e cultivar sua } \\
\text { própria confiança na criatividade. }\end{array}$ & $\begin{array}{l}1477 \quad \text { Seguidores; } 1112 \\
\text { Inspirações para ideias; } 495 \\
\text { Ideias com Aplausos; } 22 \text { Ideias } \\
\text { refinadas/avaliadas; } 9 \text { Ideias } \\
\text { vencedoras }\end{array}$ \\
\hline
\end{tabular}

Fonte: Dados da pesquisa.

A partir do Quadro 1 pode-se identificar que o desafio com maior número de seguidores é o desafio de número 10, que incentiva jovens a tornarem-se mais criativos. Este desafio vem ao encontro do exposto por Tapscott e Williams (2011) ao relatar que este novo limiar da inovação econômica e social almeja pela busca por pessoas criativas.

Observa-se também que, dos desafios lançados à comunidade, apenas 3 não foram colocados em prática, sendo que outros 7 estão em fase de realização. Tendo por base o título dos desafios, pode-se perceber o enfoque em questões sociais e ambientais. Além disso, ressalta-se que as ideias recebidas são inspirações de pessoas do mundo todo e que podem ser aplicadas nos mais diversos âmbitos e países.

A seguir, a Figura 1 demonstra a distribuição dos desafios ao longo do período pesquisado.

Figura 1: Linha do tempo dos desafios lançados no período pesquisado

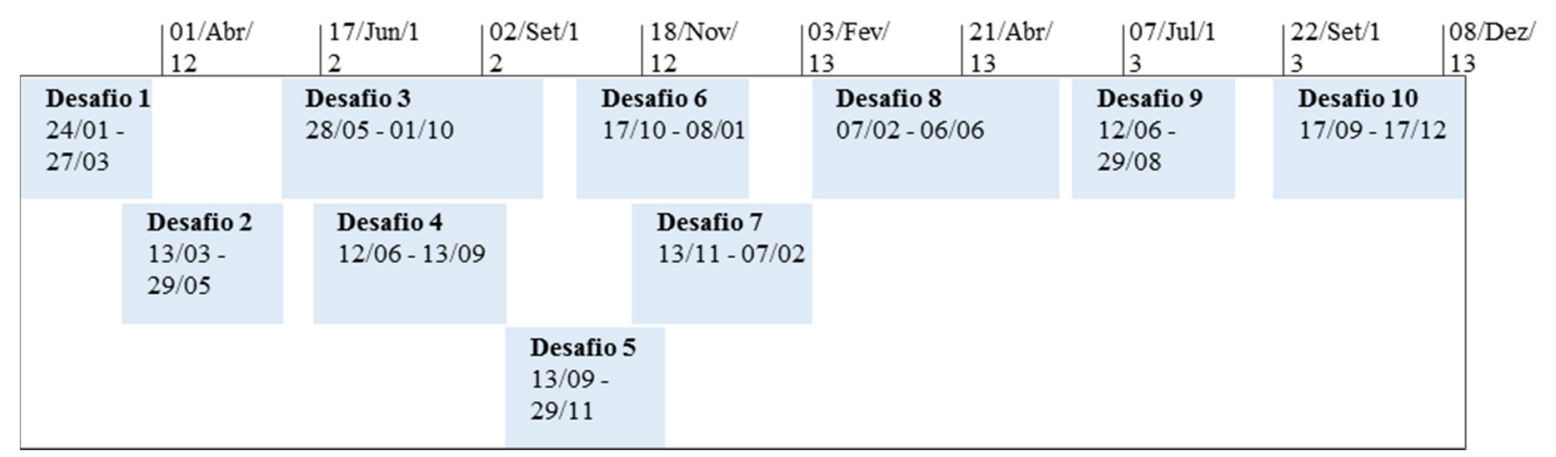

Fonte: Dados da pesquisa.

Com base na Figura 1 pode-se constatar que houve uma concentração de desafios no ano de 2012, sendo que o total de 7 desafios foram lançados neste ano. Outro fator interessante é que um desafio não precisa ter sido concluído para que outros iniciem. Este fato pode ser observado no período de 13 a 29 de novembro no qual havia 3 desafios ocorrendo de forma simultânea. No ano de 2013, entretanto, foram lançados apenas 3 desafios.

A partir dos dados disponíveis na plataforma OpenIDEO buscaram-se informações sobre temas, objetivos e beneficiários dos desafios com 0 intuito de aprofundar o mapeamento proposto. Desta forma, na apresentam-se as temáticas propostas nos desafios e seus principais enfoques. 
Figura 2: Temáticas propostas nos desafios da plataforma OpenIDEO

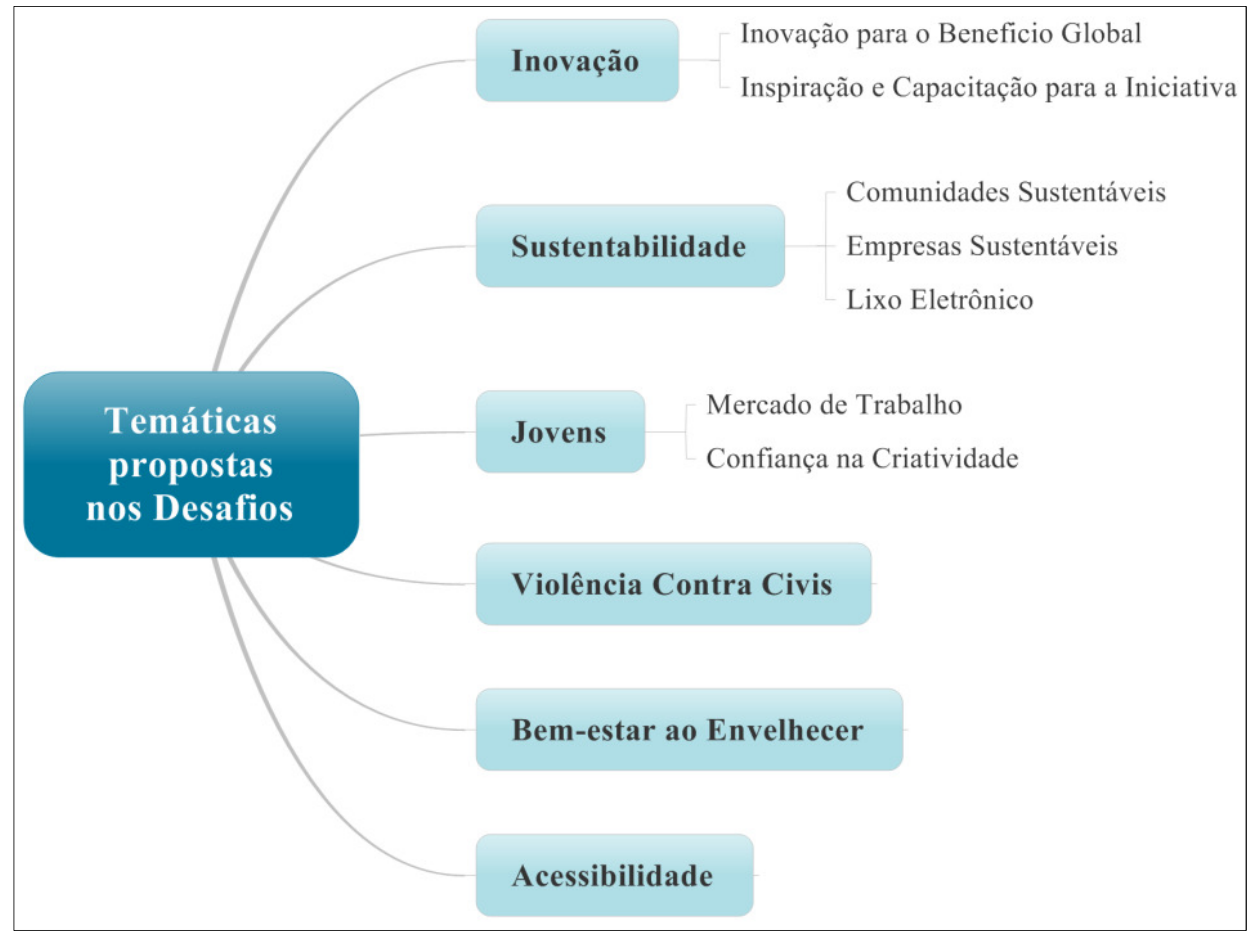

Fonte: Elaborada pelos autores.

De acordo com a Figura 2, as temáticas propostas nos desafios encontram-se distribuídas em 6 áreas principais, que são: (1) inovação; (2) sustentabilidade; (3) jovens; (4) violência contra civis; (5) bem-estar ao envelhecer; e (6) acessibilidade. Das 6 áreas temáticas abordadas, verifica-se que 3 delas (inovação, sustentabilidade e jovens) encontram-se inseridas em mais de um desafio.

Por isso, salienta-se, com base em Chesbrough (2012), que as transformações ocorridas na sociedade e o surgimento de novos conceitos na maneira de inovar, como a inovação aberta, têm instigado discussões tanto no contexto social quanto empresarial, nos últimos anos, incitando uma mudança na forma de pensar a inovação e os problemas do planeta.

Assim, em virtude da importância de cada um dos desafios e das temáticas abordadas, procurou-se considerar as informações sobre as ideias vencedoras de cada desafio, a origem dos autores, bem como 0 fato destas ideias terem sido aplicadas na fase de realização dos desafios.

A Figura 3 sinaliza os principais dados referentes ao Desafio 1. Tal desafio teve 11 ideias vencedoras, as quais foram alocadas em 3 projetos que têm por intuito o beneficiamento dos eleitores americanos, para facilitar 0 processo de votação. Os projetos desenvolvidos estão sendo implementados pelas equipes vinculadas às ideias vencedoras com o auxílio do sponsor do projeto.

Dentre as 11 ideias vencedoras, 8 são oriundas de membros da comunidade dos EUA, 2 originaram-se no Reino Unido e 1 no Camboja. Cabe destacar que esses membros se inseriram na comunidade em 2011(3) e 2012(7). Desta forma, como se trata do primeiro desafio finalizado em 2012, é provável que também seja a primeira participação destes membros como vencedores. 
Figura 3: Desafio 1

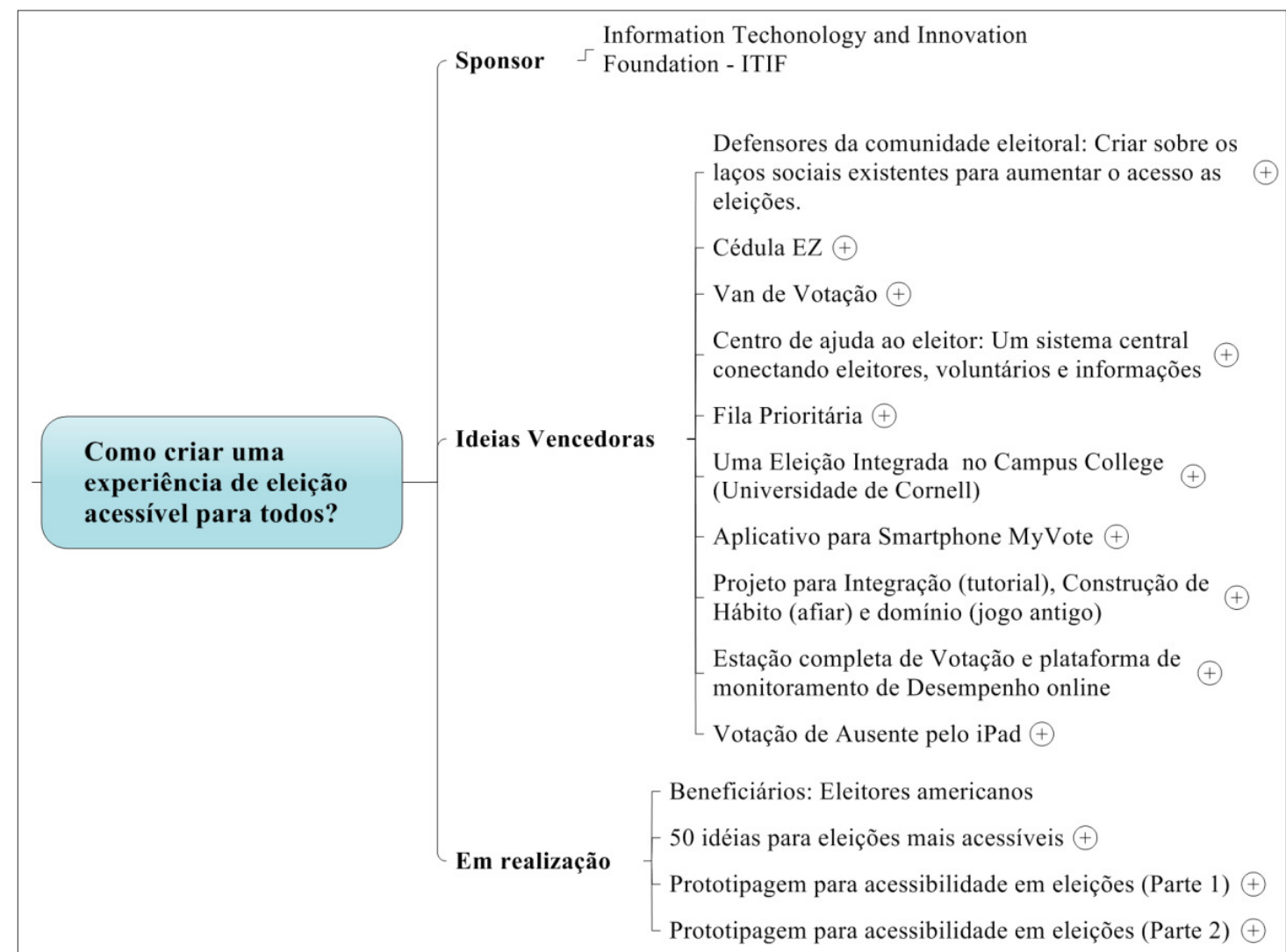

Fonte: Elaborada pelos autores.

Na sequência, a Figura 4 ilustra o Desafio 2 que teve 10 ideias vencedoras, das quais a "História da minha falha" foi prototipada conforme proposto na ideia vencedora. As demais foram combinadas e estão em realização para atingir o objetivo proposto de beneficiar startups on-line de Bruxelas e da União Europeia. As ideias vencedoras foram oriundas de quatro países: Reino Unido (5), EUA (2), Dinamarca (2) e Turquia (1). 
Figura 4: Desafio 2

\begin{tabular}{|c|c|c|}
\hline $\begin{array}{l}\text { Como podemos apoiar os } \\
\text { empreendedores da } \\
\text { internet na criação e } \\
\text { crescimento de empresas } \\
\text { globais sustentáveis? }\end{array}$ & 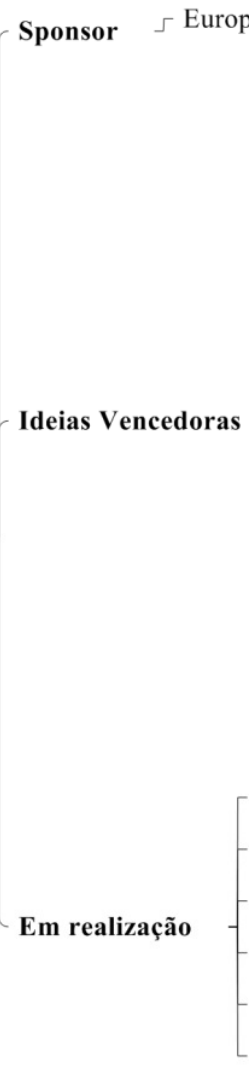 & 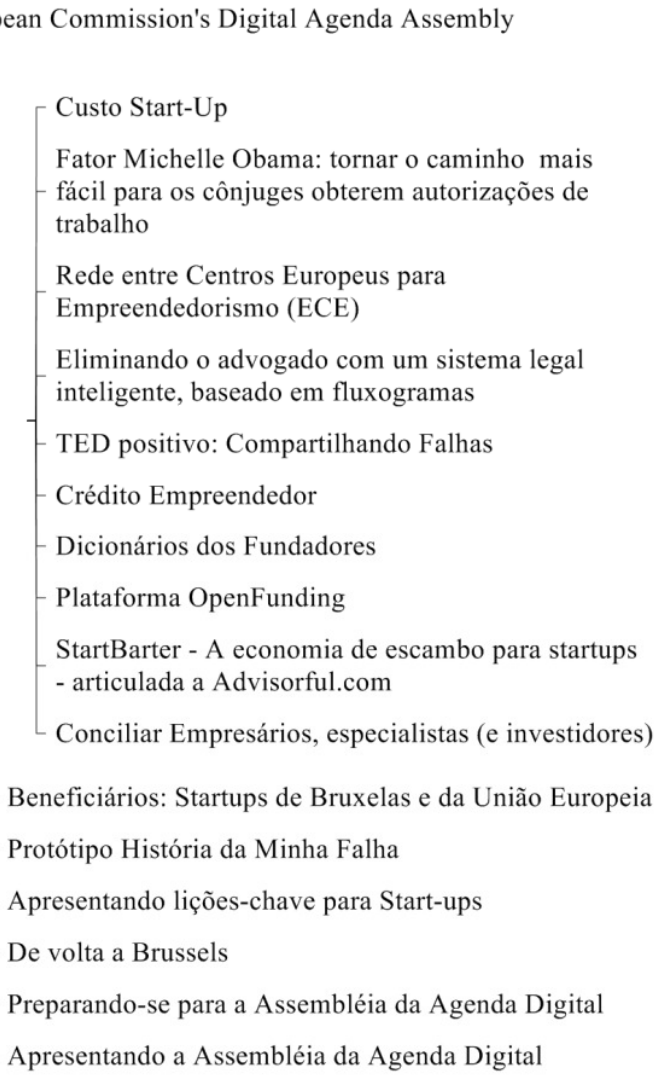 \\
\hline
\end{tabular}

Fonte: Elaborada pelos autores.

Na Figura 5 destaca-se o Desafio 3, o qual teve a participação de dois sponsors no período analisado. 0 referido desafio computou 6 ideias vencedoras, sendo que o projeto em desenvolvimento tem como beneficiários os próprios jovens que são aprendizes na organização de Barclays, um dos sponsors que contribuíram com 0 desafio. As ideias vencedoras foram procedentes de membros de 3 países: Nova Zelândia (2), Reino Unido (2) e China (1), sendo que 1 dos membros não designou seu país na plataforma OpenIDEO.

Com relação ao Desafio 3, pode-se destacar que a aplicação do projeto em sua própria empresa evidencia que as ideias geradas por meio de plataformas de inovação aberta além de beneficiar todos os envolvidos, também podem ser fonte de benefícios para o meio privado.

Figura 5: Desafio 3

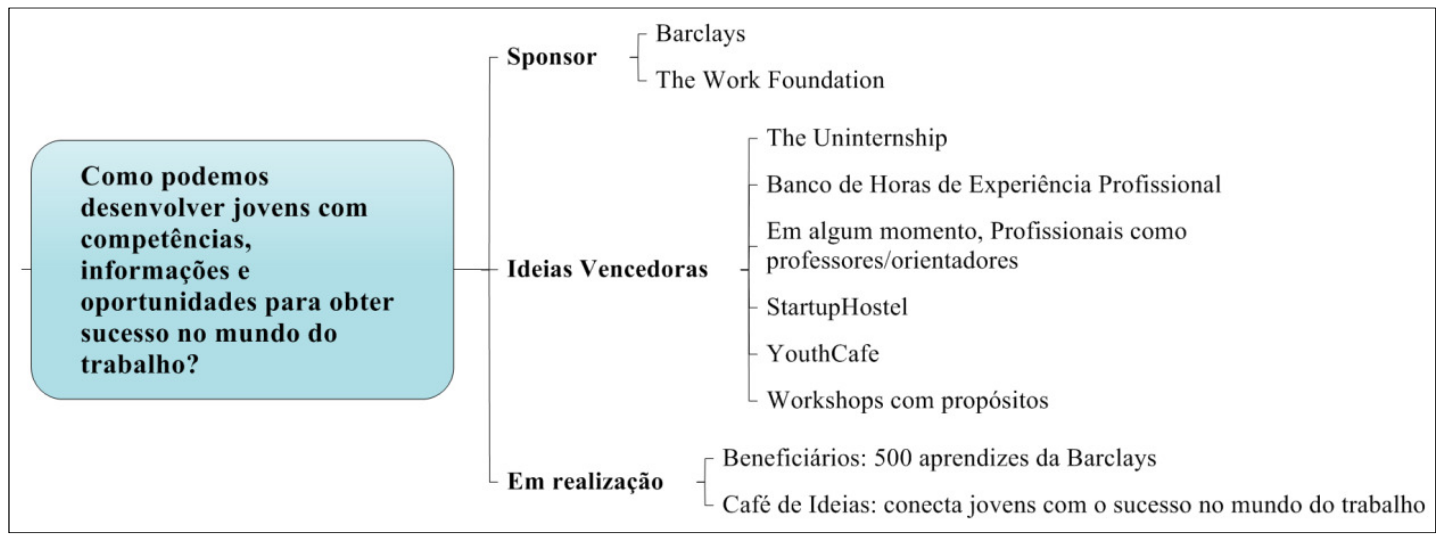

Fonte: Elaborada pelos autores. 
A Figura 6 ilustra o Desafio 4, que contou com 9 ideias vencedoras. As ideias estão sendo desenvolvidas em Londres com a utilização de conceitos diferentes das ideias vencedoras: um deles propondo uma comunidade que se baseia no lixo eletrônico para criar novos itens e novos usos para eles, e outro incentivando a redução do consumo de aparelhos eletrônicos. As ideias vencedoras foram provenientes de dois países: EUA (6) e Espanha (1) e dois membros não designaram seu país no site.

Figura 6: Desafio 4

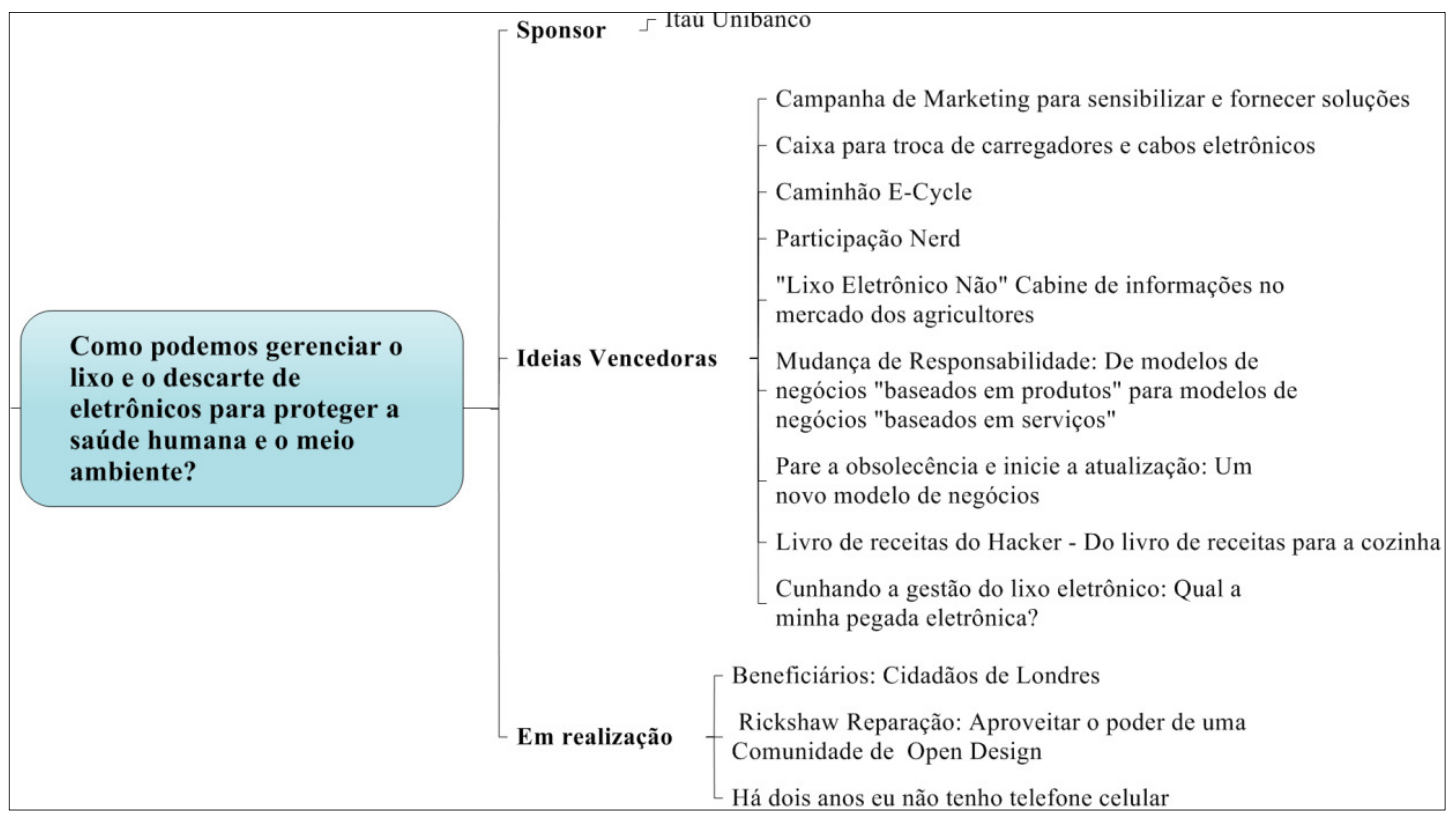

Fonte: Elaborada pelos autores.

A Figura 7 representa o Desafio 5 e as 9 ideias vencedoras que o compõem. Por meio dele, verifica-se que o desafio não foi colocado em realização pelo sponsor ou pelos membros da comunidade. No entanto, notase que a maioria das ideias vencedoras pode ser aplicada ao contexto global. As origens das ideias foram de quatro países: EUA (6), Alemanha (1), Canadá (1) e Espanha (1).

Figura 7: Desafio 5

\begin{tabular}{|c|c|c|}
\hline $\begin{array}{l}\text { Como podemos } \\
\text { identificar e celebrar as } \\
\text { empresas que inovam } \\
\text { para o benefício global e } \\
\text { inspirar outras empresas } \\
\text { a fazerem o mesmo? }\end{array}$ & $\lceil$ Sponsor $\neg$ The 1 & $\begin{array}{l}\text { wler Center For Sustainable Value } \\
\text { - Kit do Empreendedor Iniciante (ISK) e Programa de Certificação } \\
\text { - Altere isso no futuro } \\
\text { - MWB: O mestrado em benefício global } \\
\text { - Centro de artes da inovação empresarial global } \\
\text { - Quadrinhos do Bem: histórias em quadrinhos do benefício global } \\
\text { - Todos os negócios considerados } \\
\text { - Wiki para negócios com benefício global } \\
\text { Grupos de pesquisa em beneficio global e centros } \\
\text { de incubação com foco regional } \\
\text { CORPeration Commons: palco central para } \\
\text { concepção e compartilhamento de empresas que } \\
\text { geram valor sustentável }\end{array}$ \\
\hline
\end{tabular}

Fonte: Elaborada pelos autores. 
Com base na Figura 8, verifica-se que o desafio 6 conta com 10 ideias vencedoras. Tais ideias estão sendo desenvolvidas com o objetivo de proporcionar benefícios para as pessoas e para o meio ambiente. As ideias vencedoras são procedentes de quatro países: Cingapura (6), EUA (2), Bélgica (1) e Portugal (1).

Figura 8: Desafio 6

\begin{tabular}{|c|c|c|}
\hline \multirow{8}{*}{$\begin{array}{l}\text { Como podemos inspirar e } \\
\text { capacitar as comunidades } \\
\text { a ter mais iniciativas para } \\
\text { tornar seus ambientes } \\
\text { locais melhores? }\end{array}$} & \multirow[t]{6}{*}{ Sponsor } & I Environment Agency - Singapore \\
\hline & & 「 Trace: Sonhe - Desenhe - Inspire \\
\hline & & Wingpost \\
\hline & & Plataformas comunidade - As "Unvoided decks" \\
\hline & & Prato dentro - Prato Fora ( $\mathrm{O}$ que houver por uma causa) \\
\hline & & $\begin{array}{l}\text { Conectando a brincadeira ao carrossel - Um novo } \\
\text { tipo de espaço comum multi-geração }\end{array}$ \\
\hline & \multirow{5}{*}{ Ideias vencedoras } & Salões para refeições do bairro \\
\hline & & Rede inteligente de jogos Cingapura \\
\hline & & Flash Mobs para o Bem Social \\
\hline & & Biblioteca de ferramentas em cada distrito \\
\hline & & Mercado Noturno Reinventado \\
\hline & \multirow[b]{2}{*}{ - Em realização } & Beneficiários: Pessoas e o meio ambiente \\
\hline & & $\begin{array}{l}\text { pensamento crítico e a colaboração podem } \\
\text { nspirar ações produtivas }\end{array}$ \\
\hline
\end{tabular}

Fonte: Elaborada pelos autores.

O Desafio 7, apresentado na Figura 9, alcançou a quantidade de 10 ideias vencedoras. Para tanto, constatou-se que estas ideias estão em estágio de realização para beneficiar alunos e funcionários da Universidade Middlesex. Os projetos em desenvolvimento possuem dois enfoques: o primeiro visa melhorar 0 ambiente local, enquanto o segundo procura incentivar ações saudáveis que terão impacto global. As ideias vencedoras tiveram como origem 6 países: Reino Unido (3), Austrália (2), EUA (2), Cingapura (1), Índia (1) e Suécia (1).

Figura 9: Desafio 7

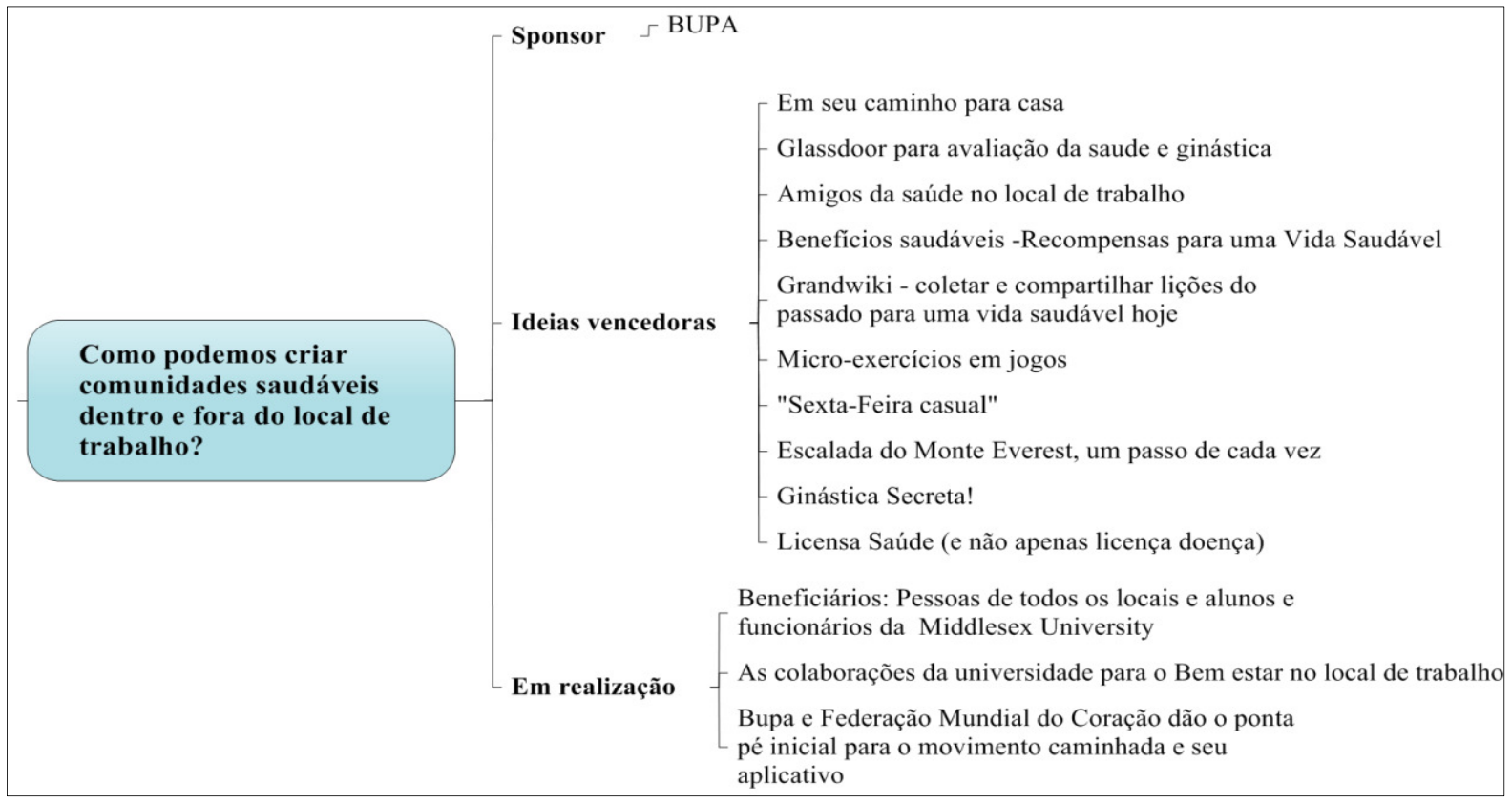

Fonte: Elaborada pelos autores. 
Na Figura 10 apresenta-se o Desafio 8 e suas 6 ideias vencedoras. Assim como no desafio 3, esse também conta com a participação de dois sponsors. Este desafio abordou a temática da violência contra civis, assunto que suscitou inúmeras discussões no ano 2012. As ideias vencedoras foram originadas em quatro países: EUA (3), Bélgica (1), Reino Unido (1) e Taiwan (1).

Figura 10: Desafio 8

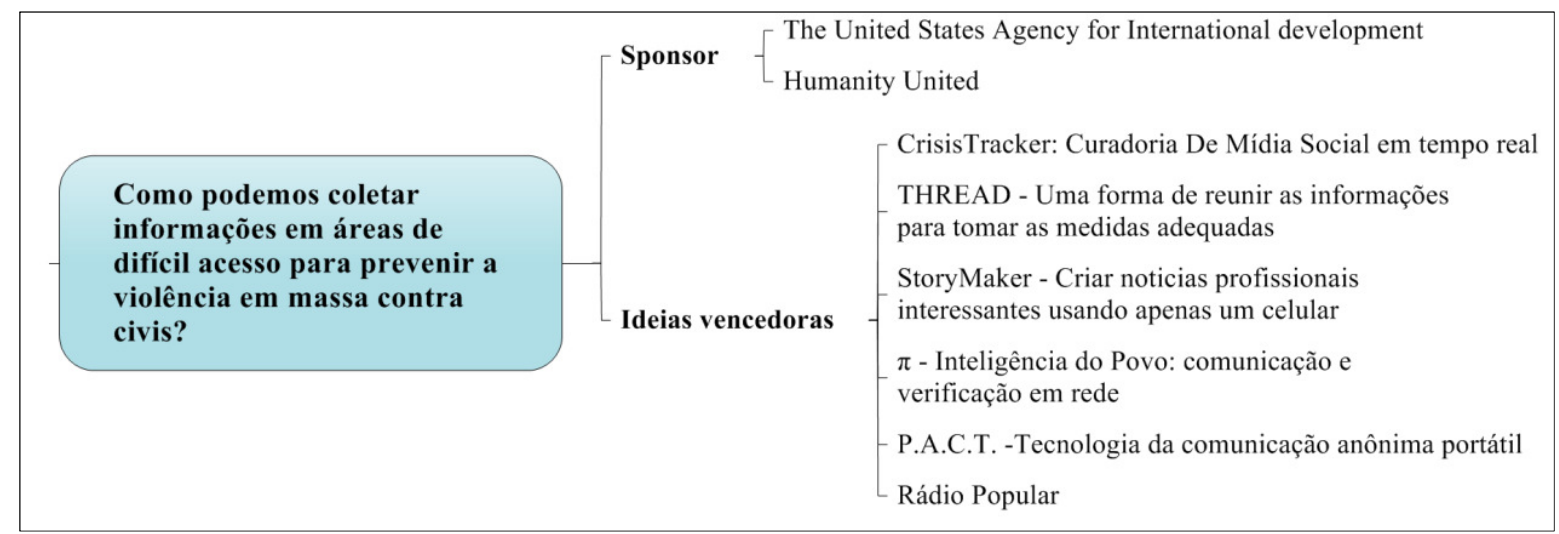

Fonte: Elaborado pelos autores.

Por meio da Figura 11 ilustram-se as 6 ideias vencedoras que compuseram o Desafio 9. As ideias foram alocadas em dois projetos que visam beneficiar os idosos e seus cuidadores. Todas as ideias vencedoras tiveram origem de membros da comunidade dos EUA.

Figura 11: Desafio 9

\begin{tabular}{|c|c|c|}
\hline \multirow{4}{*}{$\begin{array}{l}\text { Como podemos manter o } \\
\text { bem-estar e prosperar a } \\
\text { medida que envelhecemos? }\end{array}$} & \multicolumn{2}{|c|}{$\ulcorner$ Sponsor $\lrcorner$ Mayo Clinic } \\
\hline & \multirow{4}{*}{ Ideias vencedoras } & $\begin{array}{l}\text { Ferramentas de Tomada de Decisão } \\
\text { Compartilhadas: Capacitar os pacientes a tomar } \\
\text { decisões seguras } \\
\text { O jogo do sanduíche } \\
\text { - Kit de ferramentas nara o bem-estar dos cuidadores }\end{array}$ \\
\hline & & $\begin{array}{l}\text { Salão de bem estar e suporte para coordenadores } \\
\text { de comunidades saudáveis }\end{array}$ \\
\hline & & $\begin{array}{l}\text { Projetando nosso futuro: sementes participativas } \\
\text { incorporadas na comunidade madura }\end{array}$ \\
\hline & & Mais que uma visita médica, uma ponte para o bem-estar \\
\hline & & Beneficiários: Idosos e seus cuidadores \\
\hline & Em roglizocã & $\begin{array}{l}\text { Recebendo os próximos passos para o } \\
\text { Envelhecimento Saudável }\end{array}$ \\
\hline & & $\begin{array}{l}\text { Mais interação social, controle maior do ambiente } \\
\text { interno, e menos segregação por idade } \\
\text { (auto-imposta ou não) }\end{array}$ \\
\hline
\end{tabular}

Fonte: Elaborado pelos autores.

Na Figura 12 encontra-se o desafio 10, que representa o último componente pesquisado no período. Por meio de tal análise, verifica-se que o desafio contemplou 9 ideias vencedoras, oriundas de três países: EUA (7), África do Sul (1) e Índia (1). Destaca-se que o sponsor responsável por esta atividade colaborativa é a própria empresa IDEO, fundadora da plataforma OpenIDEO. 
Além disso, duas das ideias vencedoras foram elaboradas por um mesmo usuário da comunidade. Ressalta-se que este desafio foi o único no período analisado que, ao invés de apresentar os projetos por meio dos quais as ideias vencedoras são executadas, propôs-se a evidenciar os impactos desta iniciativa para a comunidade global.

Figura 12: Desafio 10

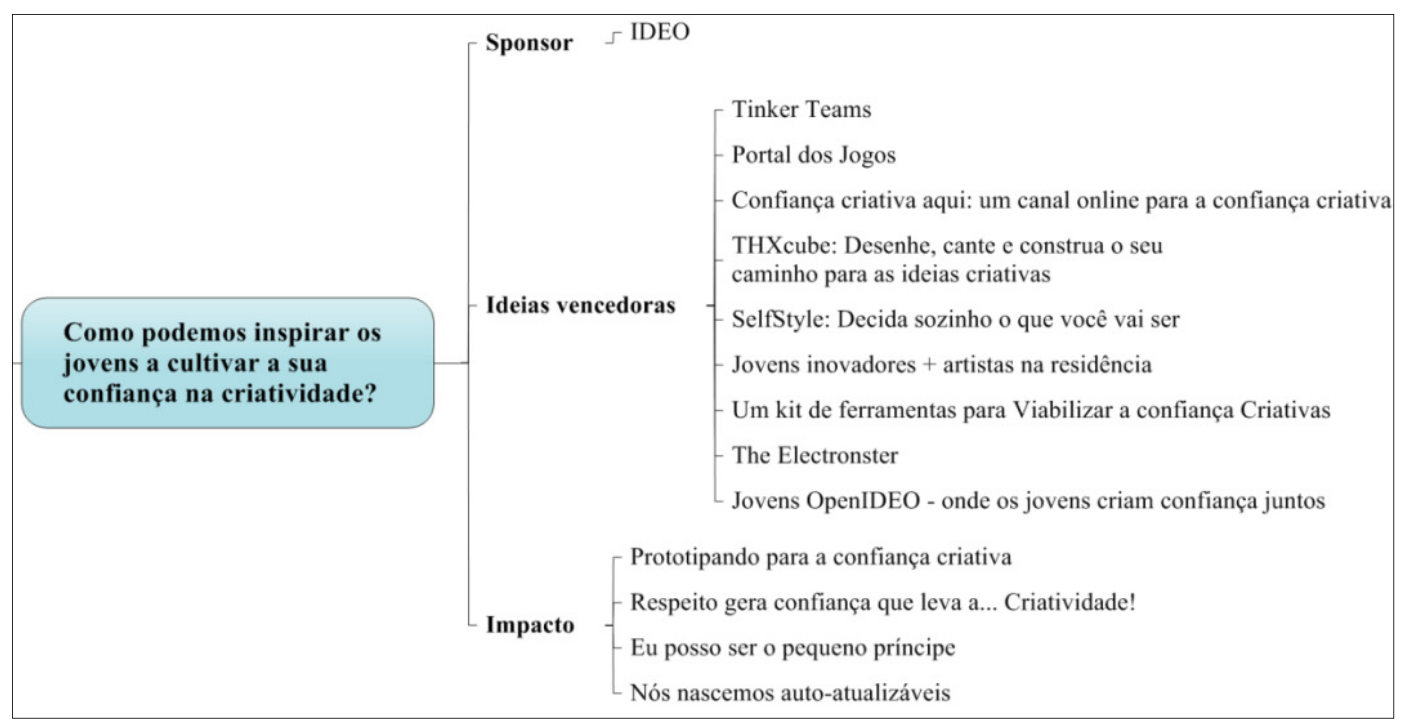

Fonte: Elaborada pelos autores.

O Desafio 10 é composto por quatro impactos que se relacionam com novas ideias, conceitos e atitudes particulares em relação à inspiração para a criatividade. Este desafio é relevante à comunidade à medida que tem a pretensão de inspirar pessoas para a aplicação prática destas ações, não necessitando, assim, ter um beneficiário diretamente envolvido.

Concluída a apresentação dos 10 desafios e suas ideias, procurou-se traçar um panorama geral dos itens analisados na plataforma OpenIDEO, os quais podem ser visualizados na Figura 13. 
Figura 13: Panorama geral dos desafios

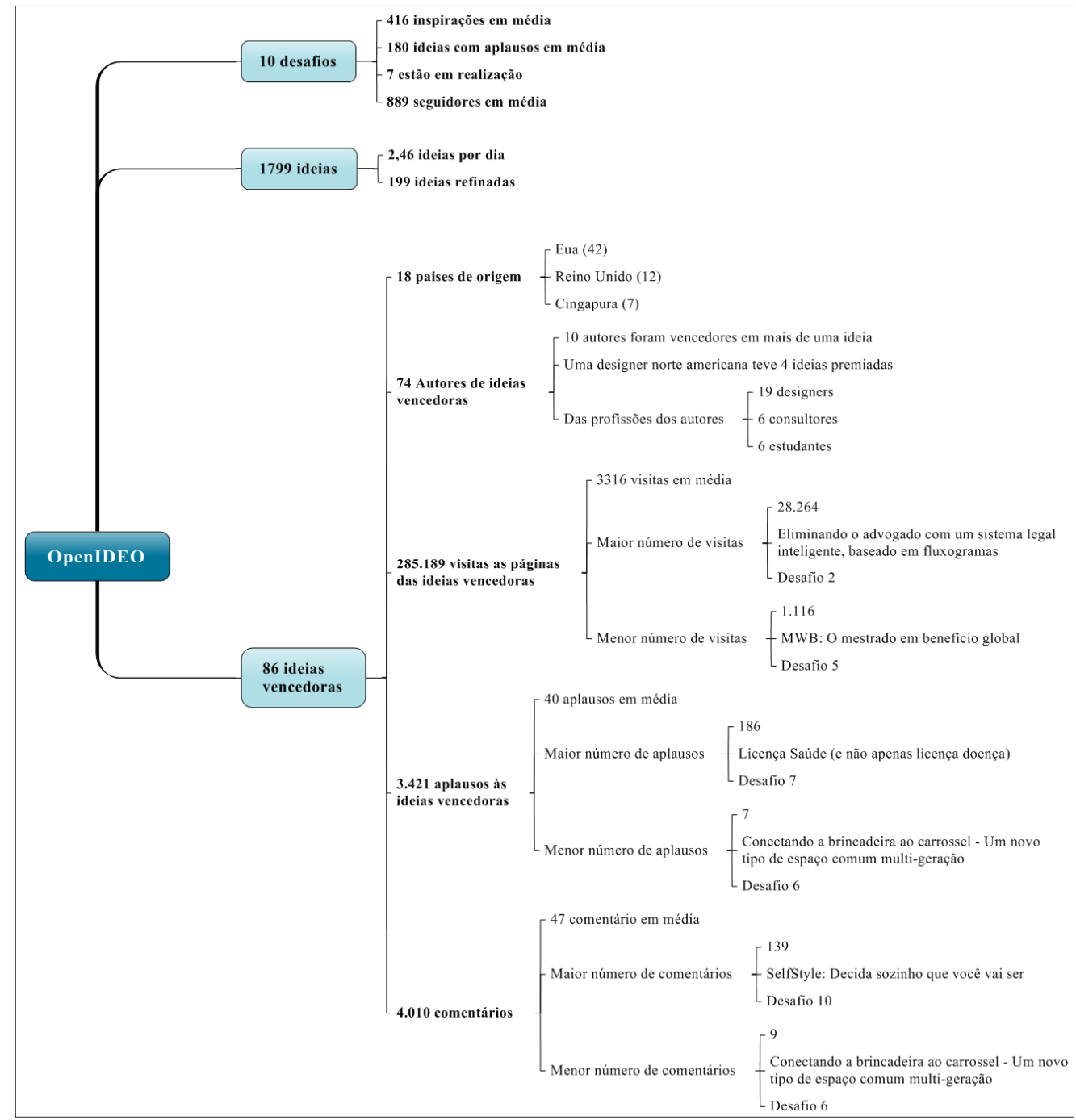

Fonte: Elaborada pelos autores.

A Figura 13 ilustra o mapeamento dos desafios lançados na plataforma OpenIDEO no período de 2012 a 2013. Nota-se que os desafios investigados possuem grande abrangência e envolvem uma considerável quantidade de pessoas, que provêm de diferentes culturas, com ideias e conceitos variados e que se envolvem na busca de soluções globais.

Cabe ressaltar que mesmo as ideias com o menor número de visitas, aplausos e comentários tiveram envolvimento da comunidade do OpenIDEO.

\section{CONSIDERAÇÕES FINAIS}

As plataformas de cocriação on-line são uma nova ferramenta para a inovação aberta. Neste cenário, destaca-se a plataforma OpenIDEO, que possibilita um intercâmbio de ideias entre pessoas e empresas de diferentes partes do mundo.

Com base nos resultados, pode-se perceber que há um significativo envolvimento da comunidade on-line com os desafios lançados, visto que todos tiveram ideias, aplausos e seguidores. Esse fato atende ao que se espera de uma plataforma aberta ou de crowdsourcing, na qual pessoas mesmo distantes geograficamente podem colaborar entre si para o desenvolvimento de ideias ou propor melhorias que não visam somente ao benefício próprio. 
A plataforma OpenIDEO mostrou-se como uma grande fonte de ideias para solucionar ou repensar diferentes temas. Como o site baseia-se em licenças do tipo creative commons, as ideias que foram postadas podem ser aplicadas, modificadas e utilizadas por qualquer pessoa em quaisquer locais do mundo. Ou seja, se uma empresa busca formas para melhorar 0 ambiente de trabalho e criar comunidades saudáveis, ela pode se basear nas ideias sugeridas ao desafio 7 para desenvolver um programa adaptado à sua realidade e às suas necessidades.

Entre as funcionalidades da plataforma, destaca-se a possibilidade de utilizar o site para buscar empregos e profissionais de diversas áreas. Assim, se uma empresa busca por profissionais que estejam envolvidos em projetos de colaboração e de benefício para a população global, a empresa pode verificar o envolvimento destas pessoas nos desafios e as ideias propostas por eles. De mesma forma, os profissionais que buscam um posicionamento no mercado de trabalho dispõem de indicativos de empresas que estão preocupadas com melhorias no ambiente em que estão inseridas, no bem-estar dos seus funcionários, bem como no futuro do planeta e não apenas com os lucros imediatos.

Como fatores restritivos desse estudo, pode-se citar a consideração de apenas dois anos para a realização do presente estudo, que se restringiu aos anos de 2012 e 2013. Além disso, não foram consideradas todas as ideias propostas para cada um dos 10 desafios e as análises realizadas não examinaram as particularidades de cada ideia.

Recomenda-se que estudos futuros realizem pesquisas comparativas entre diferentes plataformas de inovação aberta disponíveis na internet. Entre as diversas plataformas colaborativas globais, pode-se citar: Innocentive; The Postcode Lottery Green Challenge; IdeaConnection; One Billion Minds; Ideaken collaborate to innovate; Innovation Community; e Challenge.gov. Entre as iniciativas propostas no Brasil destaca-se a Tecnisa Ideias, que visa aproximar empresas de novos talentos e a plataforma marketing drops que é utilizada para 0 benefício das empresas ao sanar dúvidas e fazer sugestões sobre marketing digital.

Ainda, sugerem-se pesquisas em plataformas que possuam objetivos, diferentes da criação de ideias, como o caso da OpenIDEO. Entre essas possibilidades, pode-se elencar algumas plataformas de pesquisa e desenvolvimento, de marketing e de design. Outras, porém, são estruturadas para possibilitar previsões de mercado, busca por profissionais, inovação aberta, cocriação, bem como a criação de produtos. Além dessas encontram-se ainda plataformas que se propõe à melhoria da gestão pública.

Verificou-se que as plataformas de inovação aberta, independente de suas abordagens, atuam como um repositório de ideias que instigam a participação de milhares de pessoas e possibilitam amplo acesso e compartilhamento de conhecimento que visam proporcionar benefícios para além das fronteiras. Para tanto, destaca-se a plataforma OpenIDEO, por inserir-se neste contexto à medida que possibilita aos interessados 0 acesso e a utilização das ideias de acordo com a sua realidade e necessidade.

\section{REFERÊNCIAS}

AIGA, American Institute of Graphic Arts. Case Study: Openideo. Disponível em <http://www.aiga.org/case-studyopenideo/>. Acesso em: 26/11/2015.

BESSANT, J.; TIDD, J. Inovação e empreendedorismo. Porto Alegre: Bookman, 2009.

BEUREN, I. M. Trajetória da construção de um trabalho monográfico em contabilidade. In: BEUREN, Ilse Maria (Org.). Como elaborar trabalhos monográficos em contabilidade: teoria e prática. 2. ed. São Paulo: Atlas, 2004.

BONINI, L. A.; SBRAGIA, R. O modelo de design thinking como indutor da inovação nas empresas: um estudo empírico. Revista de Gestão e Projetos, v. 2, n. 1, 2011.

CHESBROUGH, H. Open Innovation: the new imperative for creating and profiting from technology. Boston, MA: Harvard Business School Press, 2003.

CHESBROUGH, H. Inovação aberta: como criar e lucrar com a tecnologia. (Trad.) Luiz Cláudio de Queiroz Faria. Porto Alegre: Bookman, 2012.

CHU, K-M. Motives for participation in Internet innovation intermediar Platforms. Information Processing and Management, n. 49, p. 945 - 953, 2013. 
FELIN, T.; ZENGER, T. R. Closed or open innovation? Problem solving and the governance choice. In Press. Research Policy, 2013.

GASSMANN, O.; ENKEL, E.; CHESBROUGH, H. The future of open innovation. R\&D Management, v. 40, n. 3 , p. 213-221, 2010.

GIL, A. C. Como elaborar projetos de pesquisa. 5. ed. São Paulo: Atlas, 2010.

HOWE, J. 0 poder das multidões: porque a força da coletividade está remodelando o futuro dos negócios. (Trad.) Alessandra Mussi Araújo. 2. ed. Rio de Janeiro: Elsevier, 2009.

LIMA, S. H. O.; REINALDO, H. O. A.; ABREU, M. C. S.; MURAKAMI, L. C. O Crowdsourcing como Fator de Competitividade: uma Investigação em Pequenas Empresas do Setor da Moda em Fortaleza. Revista Pensamento Contemporâneo em Administração, v. 9, n. 3, p. 138-154, 2015.

MACEDO, M. A.; MIGUEL, P. A. C.; CASAROTTO FILHO, N. A Caracterização do Design Thinking como um Modelo de Inovação. Revista de Administração e Inovação, v. 12, n. 3, p. 157-182, 2015.

MALHOTRA, N. Pesquisa de Marketing: uma orientação aplicada. 3. ed. Porto Alegre: Bookman, 2001.

RAMASWAMY, V.; GOUILLART, F. A empresa cocriativa: por que envolver stakeholders no processo de criação de valor gera mais benefícios para todos. (Trad.) Maria Lucia de Oliveira. Rio de Janeiro: Elsevier; São Paulo: Symnetics, 2010.

RICHARDSON, R. J. Pesquisa social: Métodos e Técnicas. São Paulo: Atlas, 2008.

SCHEMMANN, B.; HERRMANN, A. M.; CHAPPIN, M. M. H.; HEIMERIKS, G. J. Crowdsourcing ideas: Involving ordinary users in the ideation phaseof new product development. Research Policy, n. 45, p. 1145-1154, 2016.

SILVA, G.; SILVA, D. E. P. Inovação aberta em serviços e o papel do cliente no ambiente de negócios: uma análise com estudantes universitários. NAVUS - Revista de Gestão e Tecnologia, v. 5, n. 3, p. 74-87, 2015.

TAPSCOTT, Don; WILLIAMS, Anthony D. Macrowikinomics: reiniciando os negócios e o mundo. Trad. Afonso Celso da Cunha Serra. Rio de Janeiro: Elsevier, 2011. 